\title{
Design, synthesis and evaluation of benzofuran-acetamide scaffold as potential anticonvulsant agent
}

\author{
ASHOK K. SHAKYA $1, *$ \\ MEHNAZ KAMAL 2,3 \\ VISHAL M. BALARAMNAVAR ${ }^{4,5}$ \\ SANNA K. BARDAWEEL ${ }^{6}$ \\ RAJASHRI R. NAIK ${ }^{1}$ \\ ANIL K. SAXENA ${ }^{4,5}$ \\ H. H. SIDDIQUI ${ }^{2}$ \\ ${ }^{1}$ Faculty of Pharmacy and Medical \\ Sciences, Al-Ahliyya Amman University \\ Amman, 19328, Jordan \\ ${ }^{2}$ Faculty of Pharmacy, Integral University \\ Kursi Road, Lucknow 226026 (U. P.), India \\ ${ }^{3}$ Department of Pharmaceutical \\ Chemistry, College of Pharmacy \\ (Female Section), Prince Sattam Bin \\ Abdulaziz University, Al-Kharj 11942 \\ Kingdom of Saudi Arabia \\ ${ }^{4}$ Medicinal and Process Chemistry \\ Division, Central Drug Research Institute \\ Lucknow-226001 (U. P.), India \\ ${ }^{5}$ Department of Pharmaceutical Chemistry \\ Global Institute of Pharmaceutical \\ Education and Research, Kashipur 244713 \\ Uttarakhand, India \\ ${ }^{6}$ Faculty of Pharmacy \\ The University of Jordan, Amman, Jordan
}

Accepted January 11, 2016

Published online May 6, 2016

\begin{abstract}
A series of $N$-(2-(benzoyl/4-chlorobenzoyl)-benzofuran3-yl)-2-(substituted)-acetamide derivatives (4a-1, 5a-1) was synthesized in good yield. All synthesized compounds were in agreement with elemental and spectral data. The anticonvulsant activity of all synthesized compounds was assessed against the maximal electroshock induced seizures (MES) model in mice. Neurotoxicity was evaluated using the rotarod method. The majority of compounds exhibited anticonvulsant activity at a dose of $30 \mathrm{mg} \mathrm{kg}^{-1}$ body mass during $0.5-4 \mathrm{~h}$, indicating their ability to prevent seizure spread at low doses. Relative to phenytoin, [N-(2-(4-chlorobenzoyl)benzofuran-3-yl)-2(cyclohexyl(methyl)amino)-acetamide] (5i) and [N-(2-(4chlorobenzoyl)benzofuran-3-yl)-2-(4-methylpiperidin-1yl)-acetamide] (5c) demonstrated comparable relative anticonvulsant potency of 0.74 and 0.72 , respectively, whereas [(N-(2-(4-chlorobenzoyl)benzofuran-3-yl)-2-(4(furan-2-carbonyl)-piperazin-1-yl)-acetamide] (5f) exhibited the lowest relative potency of 0.16 . The $A L D_{50}$ of tested compounds ranged from 1.604 to $1.675 \mathrm{mmol} \mathrm{kg}^{-1}$ body mass. The $E D_{50}$ of synthesized compounds ranged from 0.055 to $0.259 \mathrm{mmol} \mathrm{kg}^{-1}$ ( 23.4 to $127.6 \mathrm{mg} \mathrm{kg}^{-1}$ ) body mass. The pharmacophore mapping of the examined compounds on standard drugs (phenobarbital, phenytoin, ralitolin and carbamazepine) strongly suggests that these compounds may exert their anticonvulsant activity via the same established mechanism as that of known drugs.
\end{abstract}

Keywords: benzofuran, anticonvulsant, neurotoxicity, GABA-AT, pharmacophore modeling, docking, Molegro Virtual Docker 4.0

Epilepsy is one of the most common and serious neurological disorders characterized by recurrent seizures resulting from a temporary electrical disturbance of the brain. Worldwide, nearly 50 million people are diagnosed with epilepsy, of which $90 \%$ of the cases occur

\footnotetext{
*Correspondence; e-mails: ashokshakya@hotmail.com; ak_shakya@ammanu.edu.jo
} 
in developing countries (1). Unfortunately, 20-30 \% of epileptic patients have seizures that are resistant to available medical therapies. In addition, all currently approved antiepileptic drugs have dose related toxicity and idiosyncratic side effects (2). The most commonly reported side effects are drowsiness, ataxia, gastrointestinal disturbances, hepatotoxicity, gingival hyperplasia, hirsutism and megaloblastic anaemia $(3,4)$. Phenytoin, carbamazepine, lamotrigine, sulfamate and topiramate are recent antiepileptic drugs clinically effective against different types of seizures (5). Despite rapid progress in the development of new antiepileptic compounds, no single treatment is satisfactory in preventing and controlling seizures (6-8). Therefore, developing new antiepileptic agents with improved therapeutic properties has been the focus of research groups and a hot target for medicinal chemists.

Amides are a class of compounds presenting a wide range of biological applications and anticonvulsant activity $(9,10)$. It has been reported earlier (11) that anticonvulsant compounds require the following essential features: (i) a hydrophobic aryl ring, (ii) a hydrogen bonding domain, (iii) an electron donor acceptor system and (iv) another hydrophobic aryl ring responsible for the metabolism. These essential features are present in most popular anticonvulsant drugs such as phenytoin, carbamazepine, phenobarbital and ralitoline. Benzofuran derivatives have diverse pharmacological activities, like anticonvulsant (12-15), antiinflammatory (13), analgesic (16), antioxidant and antimicrobial (17, 18), neuroprotective (19), anticancer, cytotoxic, inhibiting of NF- $\kappa B$ and protein kinase (20-22). Benzofuran, a versatile heterocyclic molecule possessing a preliminary anticonvulsant property, has been selected to explore as a hydrophobic functional group for the binding site.

Gamma-aminobutyric acid (GABA) is the main neurotransmitter in the CNS responsible for the maintenance of the inhibitory tone that counterbalances neuronal excitation. A GABA antagonist causes seizures while a GABA agonist suppresses seizures. Most anticonvulsant drugs possess activity via GABA mediation. Keeping this in mind, active compounds were screened for neurochemical estimation of the GABA level in brain.

In the present work, our objective was to design and synthesize new compounds having benzofuran moiety coupled with substituted amines via acetamide linkage hoping to get compounds with enhanced bioactivity and to study their binding properties with $\gamma$-aminobutyric acid-aminotransferase (GABA-AT). All the compounds were evaluated for their antiepileptic and neurotoxic properties according to the protocols of the Antiepileptic Drug Development (ADD) program developed by the National Institute of Health (NIH). In order to explore the common pharmacophore of these compounds, we investigated the synthesized series of compounds by means of the computer aided drug design through ligand based approaches. Pharmacophore modeling tool was selected for this study.

The literature reveals a large number of successful applications of the pharmacophore based virtual screening protocols in the modern drug discovery paradigm $(23,24)$. The Hip Hop algorithm finds the common feature pharmacophore model in the set of highly active ligands and is thus regarded as qualitative model without the use of activity data representing the 3D arrangement of the essential features important for the specific activity. The molecular docking approach is one of the most rational and authentic approaches in drug design and discovery for studying molecular interactions of small molecules. Docking involves two main components, the search algorithm and scoring functions. The search algorithm involves the positioning of molecular conformations in the active site while the scoring function determines energetically most favourable orientation of the molecule. In this study, we have used the Molegro virtual docker 4.0 program with its piecewise linear potential (PLP) based algorithm for docking of all synthesized com- 
pounds in the GABA-AT binding site, which was also previously reported by many authors $(25,26)$. We have also calculated the binding affinities of these compounds compared to standard reference compounds.

\section{EXPERIMENTAL}

\section{Chemistry}

All the chemicals and solvents used in the study were purchased from Merck (Germany), Sigma-Aldrich (USA/India) and Acros (Belgium) and were used without further purification. Melting points were determined in open glass capillaries using a melting point apparatus (Veego, India) and were uncorrected. The IR spectra were measured using a Mattson ATI Genesis FT-IR Spectrometer (Mattson Instruments, USA). ${ }^{1} \mathrm{H}$ NMR and ${ }^{13} \mathrm{C}$ NMR spectra of selected compounds were recorded on a Bruker model DRX-300 NMR spectrometer (Bruker BioSpin Corporation, USA) in $\mathrm{CDCl}_{3} / \mathrm{DMSO}-d_{6}$ using tetramethylsilane (TMS) as internal reference. Chemical shifts are reported in parts per million (ppm, $\delta$ ) and signals are described as s (singlet), $\mathrm{d}$ (doublet), $\mathrm{t}$ (triplet), q (quartet) and $\mathrm{m}$ (multiplet). The electrospray mass spectra were recorded on a Micromass Quattro II triple-quadrupole mass spectrometer (Micromass, UK). Elemental analyses $(\mathrm{C}, \mathrm{H}$ and $\mathrm{N}$ ) were performed on a Perkin-Elmer model 240 analyzer (PerkinElmer, USA) and were found within the range of $\pm 0.4 \%$ of theoretical values. Purity of the compounds and the progress of reaction were checked by thin layer chromatography (TLC) on silica gel G plates (Qualigens, India) using cyclohexane/ethyl acetate (8:2) as a solvent system and the spots were located either under UV light or by exposure to iodine vapors.

\section{Syntheses}

2-(Benzoyl-methoxy)benzonitrile (1a), 2-[2-(4-chlorophenyl)-2-oxyethoxy]benzonitrile (1) $)$, 2-benzoyl-1-benzofuran-3-amine (2a) and 2-(4-chlorobenzoyl)-1-benzofuran-3-amine (2b) and $\mathrm{N}-(2-$ benzoyl-benzofuran-3-yl)-2-chloroacetamide (3a) were prepared following the reported methods $(12,16)$.

$\mathrm{N}$-(2-(4-chlorobenzoyl)benzofuran-3-yl)-2-chloroacetamide (3b). - 3-Amino-2-(4-chlorobenzoyl)benzofuran (2b, $20 \mathrm{mmol}$ ) and 4-dimethylamino-pyridine (DIMAP, $2 \mathrm{mmol}$ ) were dissolved in dioxane $(20 \mathrm{~mL})$. Chloroacetyl chloride $(22 \mathrm{mmol})$ was added in small portions for $30 \mathrm{~min}$. The reaction mixture was stirred at room temperature and then warmed on a water bath for $5 \mathrm{~h}$. After cooling, reaction mixture was poured into ice water with stirring. The solid that separated was collected and recrystallized from benzene.

N-(2-(benzoyl/4-chlorobenzoyl)benzofuran-3-yl)-2-(substituted)-acetamides (4a-1, 5a-1). General procedure. - To a well stirred solution of $\mathrm{N}$-(2-(4-benzoyl/4-chlorobenzoyl)benzofuran-3-yl)2-chloroacetamide $(3 \mathbf{a} / 3 \mathbf{b}, 1 \mathrm{mmol})$ in dioxane $(10 \mathrm{~mL})$, different amines $(2 \mathrm{mmol})$ were added separately and the reaction mixture was refluxed for $4 \mathrm{~h}$. The reaction mixture was cooled and poured in water. The residue which separated was collected and recrystallized from ethanol.

The physicochemical properties and spectral data of synthesized compounds $3 \mathbf{b}, \mathbf{4} \mathbf{a}-\mathbf{1}$, $5 a-1$ are given in Table I. 


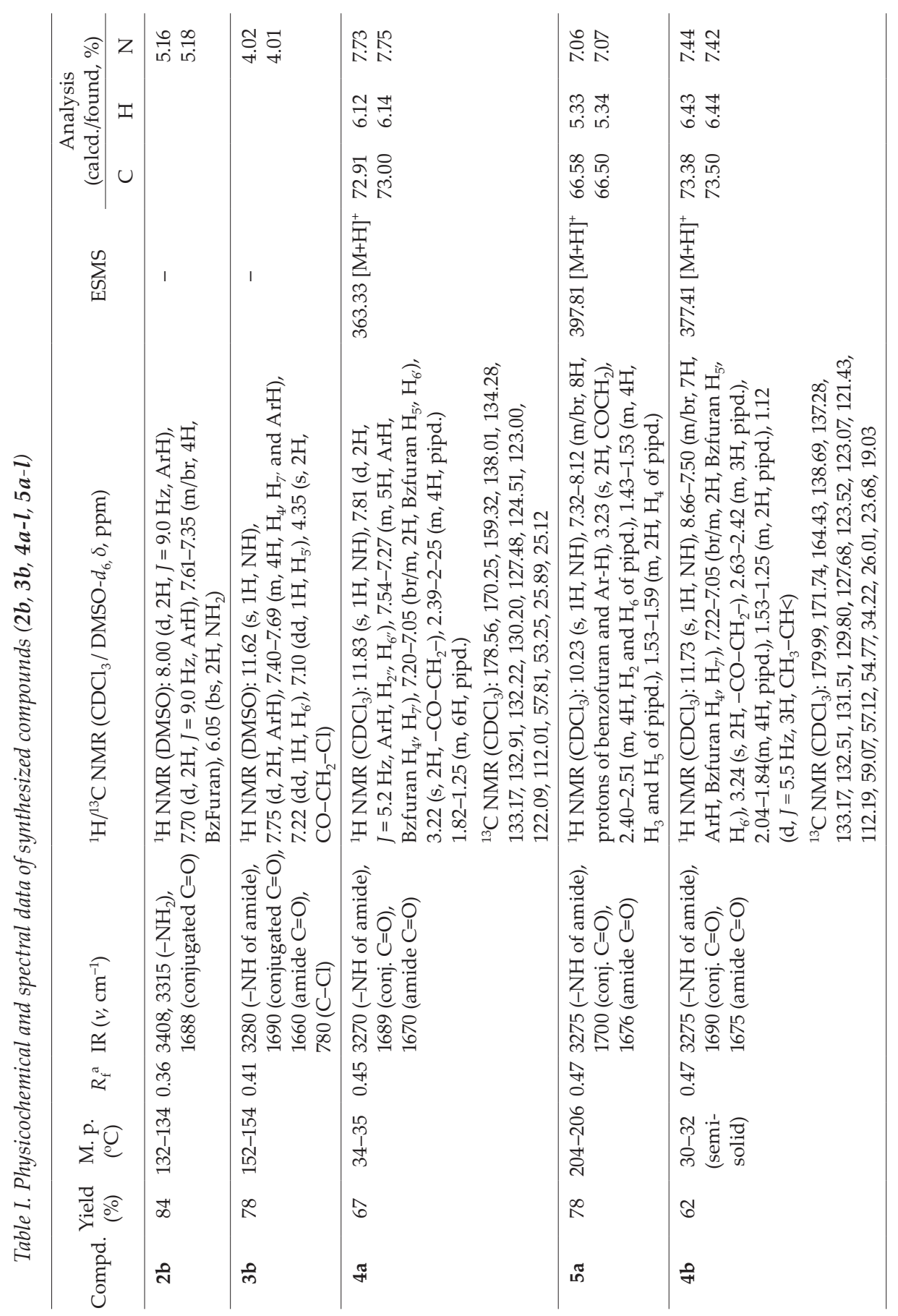




\begin{tabular}{|c|c|c|c|c|}
\hline 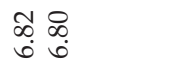 & 埜亮 & $\begin{array}{lll}\alpha & \infty \\
0 & \infty \\
0 & 0\end{array}$ & 곳 & مी \\
\hline $\begin{array}{l}\text { ț } \\
\text { மீं }\end{array}$ & 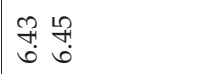 & $\begin{array}{l}\text { to to } \\
\text { in }\end{array}$ & 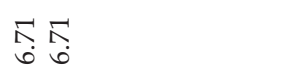 & 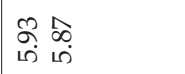 \\
\hline 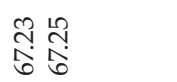 & 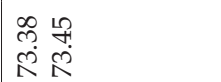 & 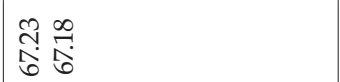 & 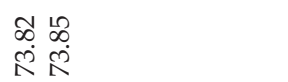 & 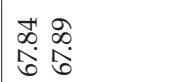 \\
\hline 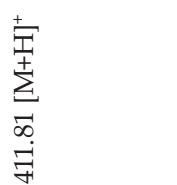 & 壹 & 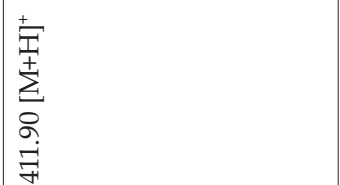 & 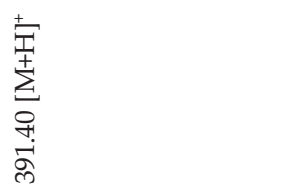 & 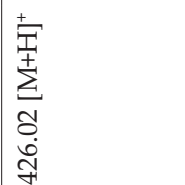 \\
\hline 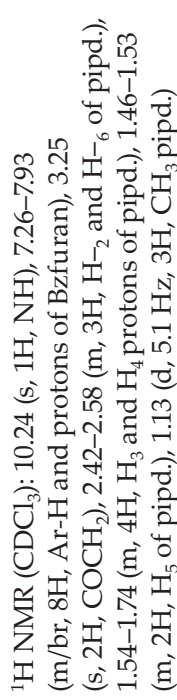 & 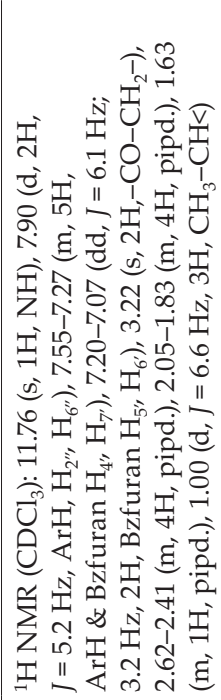 & 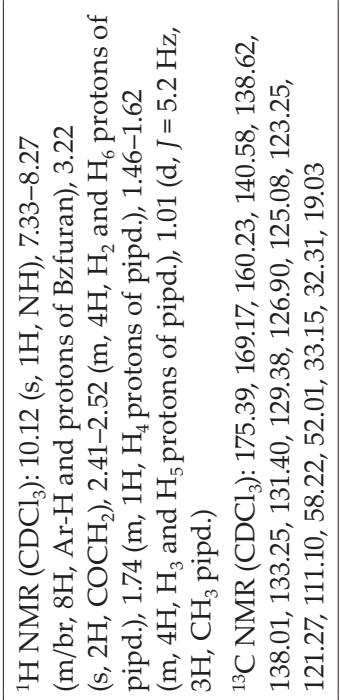 & 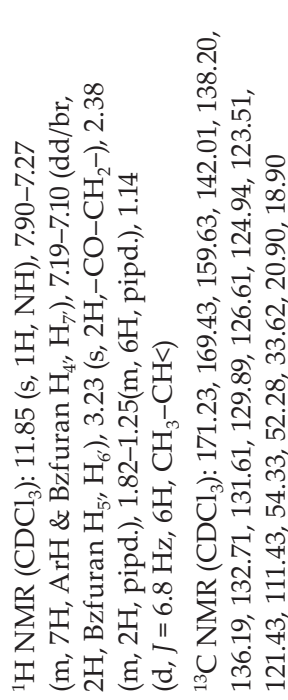 & 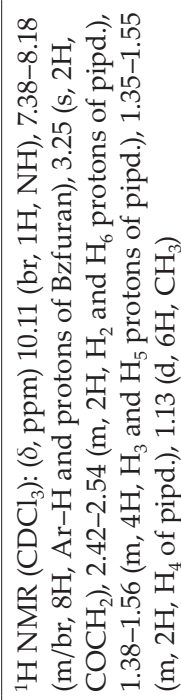 \\
\hline 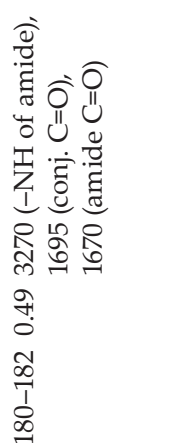 & 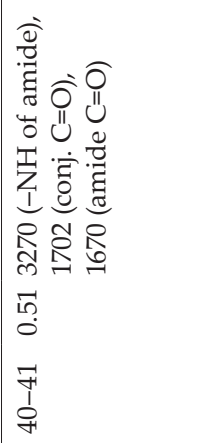 & 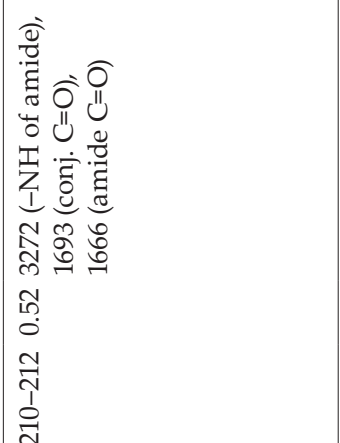 & 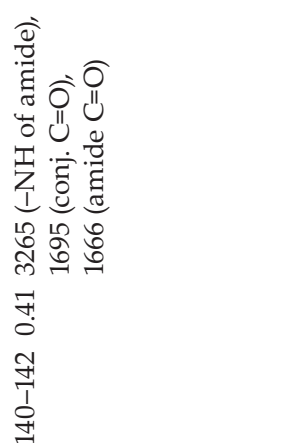 & 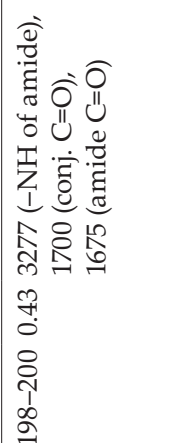 \\
\hline$N$ & 18 & $\infty$ & $\stackrel{\infty}{\infty}$ & $\kappa$ \\
\hline in & y & ڤ̆ & $\bar{T}$ & I \\
\hline
\end{tabular}




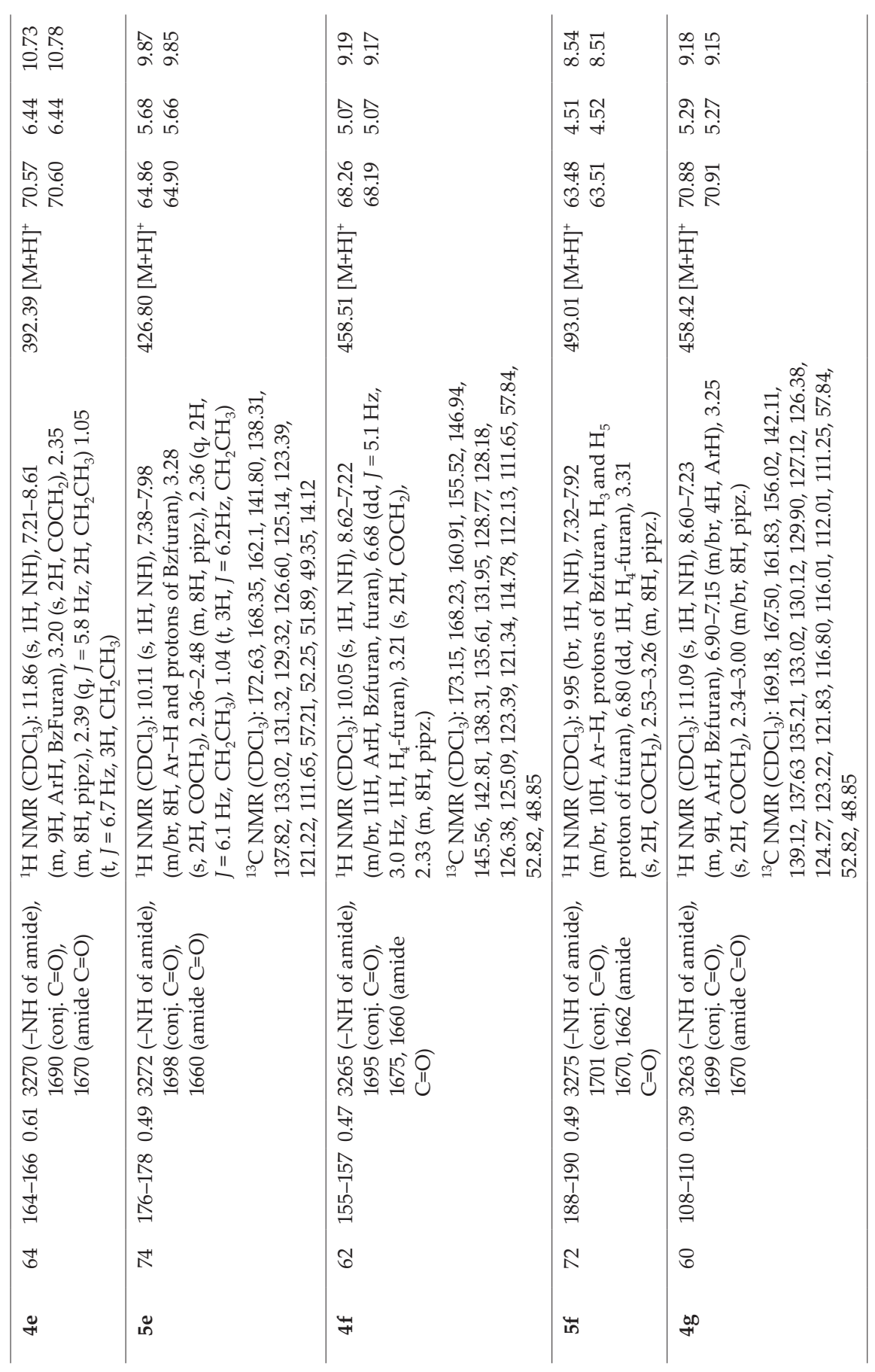




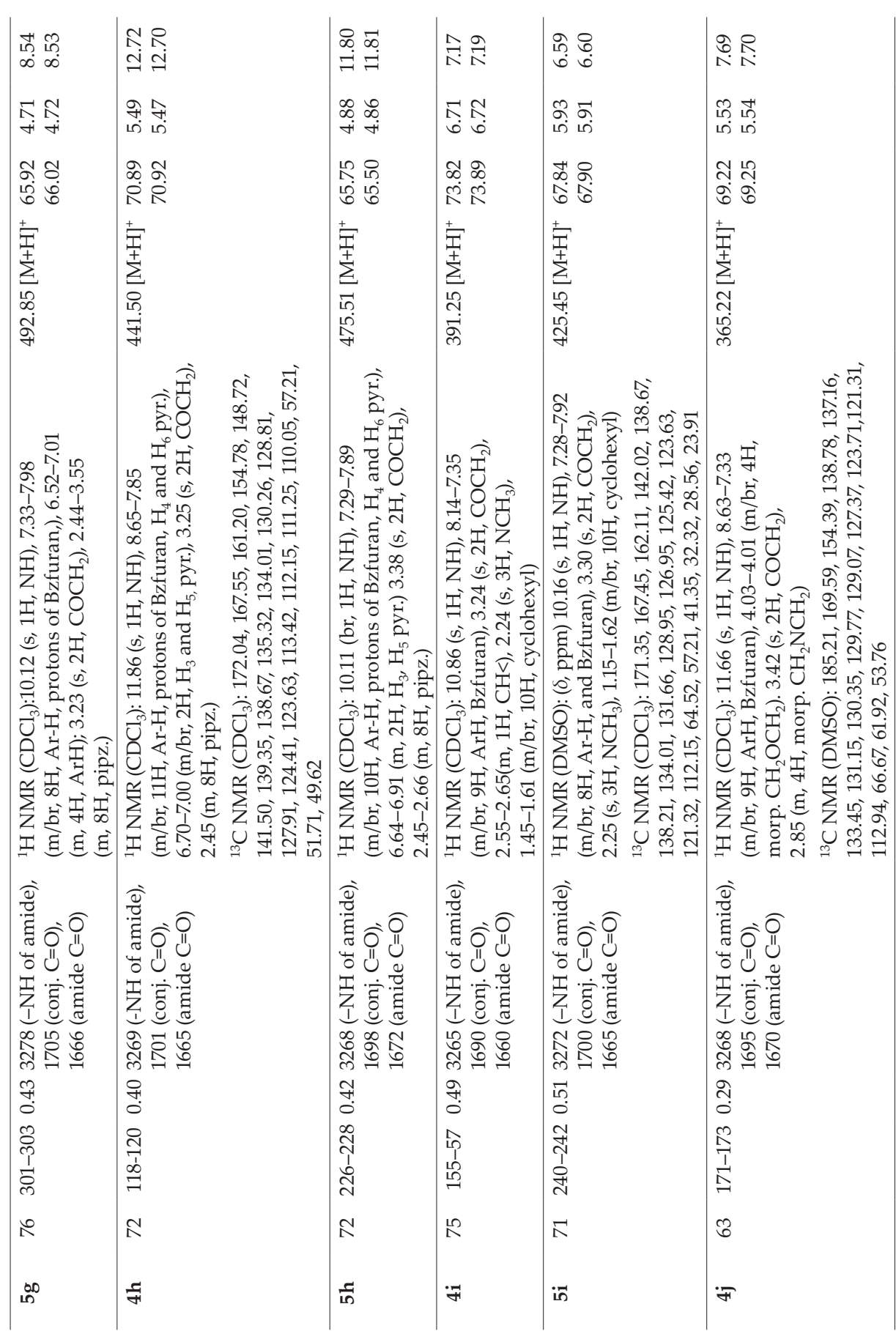




\begin{tabular}{|c|c|c|c|c|}
\hline 究 & 궁 न्: & 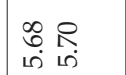 & 异 & 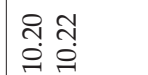 \\
\hline 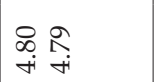 & 岱胥 & 点 & 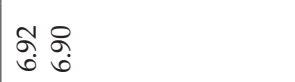 & 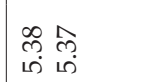 \\
\hline 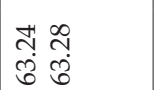 & 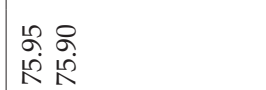 & 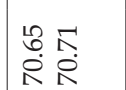 & 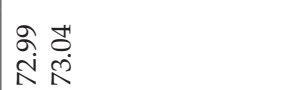 & 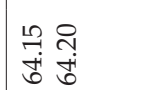 \\
\hline & 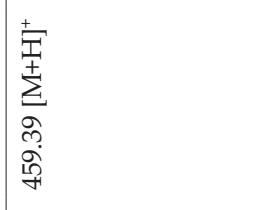 & 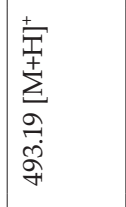 & 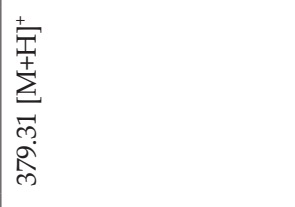 & 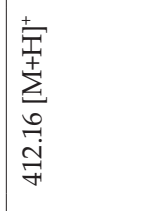 \\
\hline 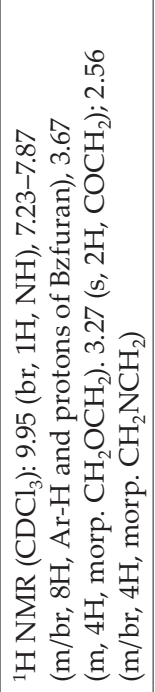 & 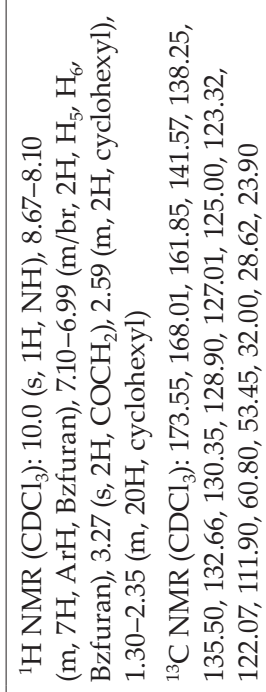 & 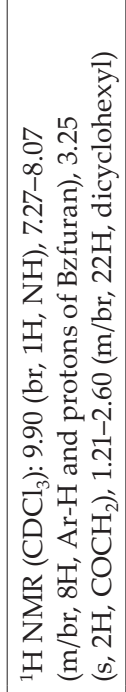 & 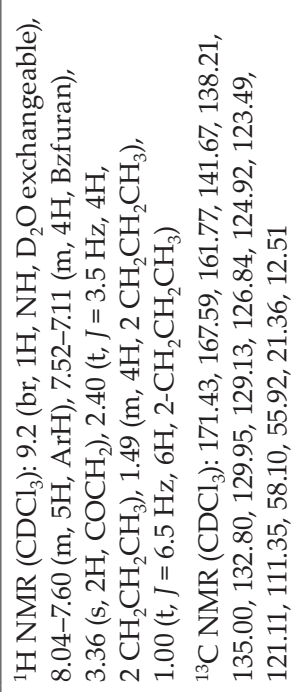 & 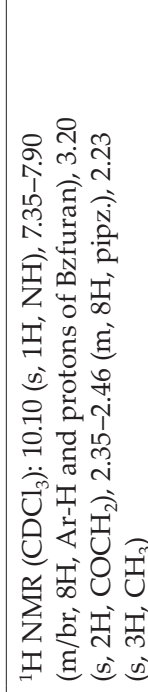 \\
\hline 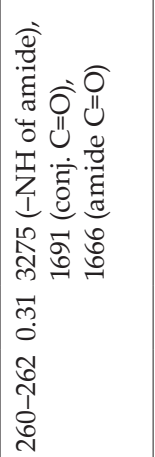 & 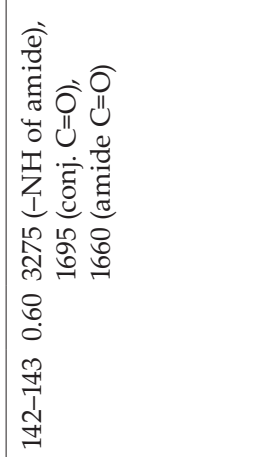 & 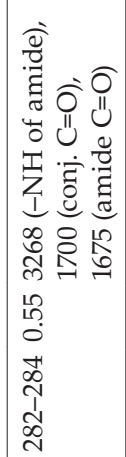 & 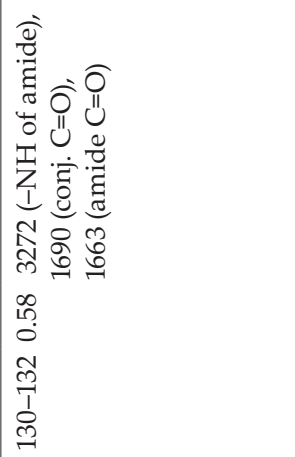 & 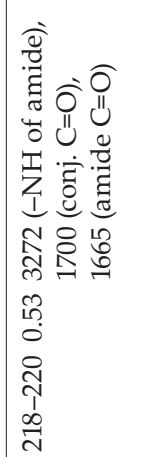 \\
\hline 8 & in & H & $\stackrel{\infty}{i}$ & $\stackrel{2}{\mathfrak{2}}$ \\
\hline in & $\breve{F}$ & 는 & $F$ & के \\
\hline
\end{tabular}




\section{Pharmacology}

Animals and general procedures. - Male albino Swiss mice (20-30 g) and Wistar rats (125-160 g) were used as experimental animals. Animals were housed and kept in accordance with the Integral University Lucknow animal care unit. Experiments were approved by the institutional Ethical Committee. The animals were housed in groups of 6 animals and acclimatized to room conditions for at least 2 days prior to the experiments. Anticonvulsant evaluations were undertaken using the reported procedure (27). Test compounds and the standard drug (in $0.5 \%$ methylcellulose) were administered intraperitoneally. The rotarod test was used to evaluate neurotoxicity (28). The level of GABA in brain tissues of rats was estimated enzymatically as previously described (29). Approximate lethal dose $\left(A L D_{50}\right)$ of the selected compounds was determined according to the literature (30).

Anticonvulsant activity. - Animals (mice) were maintained at an adequate diet and allowed free access to food and water except for a short period during which they were removed from the cages for testing. The animals were screened 24 hours prior to experiment. A $50-\mathrm{mA}$ current was given to the pinna of the animals for $0.25 \mathrm{~s}$ using a Medicraft ${ }^{\circledR}$ Electro-Convulseometer (Medicraft Electro Medicals (P) Ltd, India). Normal saline was used as the conducting medium between the electrode and pinna. Only those animals which produced tonic convulsions were selected. The maximal seizure usually consisted of a short period of tonic extension of the hind limbs and the final clonic episode. Next day, the selected animals were divided into groups and compounds were administered intraperitoneally (doses of 30, 100 or $300 \mathrm{mg} \mathrm{kg}^{-1}$ body mass). After $30 \mathrm{~min}$ and 4 hours of drug administration, electroshock was applied. Disappearance of the hind limb tonic extensor component of convulsion was considered positive criterion for anticonvulsant activity.

Neurotoxicity screening. - Minimal motor impairment was measured in mice by the rotarod test. The mice were trained to stay on an accelerating knurled rod (diameter 3.2 $\mathrm{cm}$ ) rotating at 6 revolutions per min. Only those animals which demonstrated their capability to remain on the revolving rod for at least $1 \mathrm{~min}$ were considered for the test; these mice were considered as trained mice. Trained mice can remain on a rod rotating at this speed indefinitely. These trained mice were given test compounds or phenytoin in doses of 30,100 and $300 \mathrm{mg} \mathrm{kg}^{-1}$. Thirty minutes after administration, the mice were placed on the rotating rod. Neurological toxicity is defined as the failure of the animal to remain on the rod for at least $1 \mathrm{~min}$ in each of the three trials.

In order to explore the mechanism of anticonvulsant activity of these derivatives, most active compounds ( $5 \mathbf{i}$ and $\mathbf{5 c}$ ) were subjected to neurochemical investigation to determine the GABA level in brain tissue extracts.

GABA level in brain. - Adult Wistar rats were divided into three groups of three animals each. After $2 \mathrm{~h}$ of clobazam ( $30 \mathrm{mg} \mathrm{kg}^{-1}$ body mass) or test compound (5c or $5 \mathbf{i}, 100 \mathrm{mg}$ $\mathrm{kg}^{-1}$ body mass) administration, the animals were decapitated and the brain regions, mid brain, cerebellum and medulla oblongata were dropped into separate vessels containing $4 \sim 6 \mathrm{~mL}$ of ice cold $80 \%$ ethanol and processed further as per the reported procedure (29).

The effective $50 \%$ dose values $\left(E D_{50}\right)$ of compounds were calculated using the XLSTAT software version 2012.2.01 (Addinsoft, Paris, France) on the basis of maximum effect observed after $0.5 \mathrm{~h}$. 
Lethal dose $\left(L D_{50}\right)$. - The animals (mice) were divided into different groups of four animals each. These were administered 215, 464, 1000 and $2150 \mathrm{mg} \mathrm{kg}^{-1}$ of drugs intraperitoneally and observations were made for mortality up to 24 hours. The lethal dose was calculated as reported earlier (30).

\section{Computational methods}

All molecular modeling works were accomplished using the Window-based Accelrys Discovery Studio version 2.0 (DS 2.0, Accelrys Inc., USA). All structures were generated using the 2D/3D editor minimized to the closest minimum using the CHARMM-like force field implemented in the program (31). Stochastic method coupled with poling algorithm was used to generate conformers for each compound by using the best conformation generation method with $20 \mathrm{kcal} \mathrm{mol}^{-1}$ energy cutoff. The catalyst based pharmacophore generation involved the HipHop algorithm for the generation of 3D pharmacophore alignment. The procedure for the generation of pharmacophore involved as per reported protocols generation of a conformational model for each training set of compounds followed by examination of each conformation for the presence of important chemical features (31). Finally, a 3D configuration of a chemical feature common to the input molecules was determined. Catalyst defines the important feature of compounds in the drug-enzyme/receptor interactions. These are hydrogen bond donors, hydrogen bond acceptors, hydrophobic groups, aromatic ring and positive and negative ionisable groups. For the pharmacophore modeling runs, common features selected for the run were ring aromatic (R), hydrogen bond donor (D), hydrogen bond acceptor (A), hydrophobic group (H), positive ionisable group $(\mathrm{P})$.

\section{Molecular modeling and docking studies}

Moldock software version 4.1.0 (CLC bio, Aarhus, Denmark) combines the differential evolution algorithm with the cavity prediction algorithm. Previously, only differential evolution was applied to molecular docking, which, when combined with the cavity prediction algorithm, results in fast and accurate binding modes. The scoring function in Moldock is based on the Piecewise Linear Potential (PLP), which was introduced by Gehlhaar et al. (32) and further extended by Yang and Chen (33) in GEMDOCK. In this case, the hydrogen bond directionality was taken in account to improve the Moldock scoring functions. The reported co-crystal structure of 4-aminobutyrate-aminotransferase (GABA-AT) from pig (1OHV) was obtained from Brookhaven Protein Data Bank (PDB). The PDB ID $1 \mathrm{OHV}$ was prepared using the docking algorithm by assigning the bond orders, if missing, charges and flexible torsions. This protein was again prepared initially by considering the protein without ligand and water molecules. The backbone was fixed, the CharmM force field and minimization using the steep descent algorithm were applied for 1OHV. This prepared protein structure was used for docking experiments. The structures of two most active compounds used in this study were drawn in Chemdraw ultra 12 and imported in Discovery Studio 2.0 (Telesis Court, San Diego, CA, USA) for minimizing it up to a gradient of $0.01 \mathrm{kcal} \mathrm{mol}^{-1} \AA^{-1}$ using the CharmM forces field. In the Molegro docking wizard, the prepared protein was imported and potential binding sites were calculated using the cavity detection algorithm in the Moldock optimizer. The radius of the docking search sphere was set to $10 \AA$ around Lys-329 since vigabtrin, the standard drug, forms a covalent ter- 
nary adduct with the active site Lys-329. The cavity detection algorithm (guided differential evolution) was used to focus the search during docking runs. The parameters were fixed for docking runs as: number of runs 10 , population size 50 , crossover rate 0.9 , scaling factor 0.5 and maximum iterations 2000. To retain the best scoring pose, pose clustering was applied and the best five top scoring poses were retained. Fitness scores calculated by the Moldock scoring 0.5 function were then evaluated.

\section{RESULTS AND DISCUSSION}

\section{Chemistry}

The title compounds, $N$-(2-(4-benzoyl/chlorobenzoyl)benzofuran-3-yl)-2-(substituted)-acetamides (4a-1, 5a-1) were synthesized (Scheme 1) by refluxing 2-chloro- $N$-(2-(4-benzoyl/chlorobenzoyl)benzofuran-3-yl)-acetamide (3a or $3 \mathbf{b}$ ) with various substituted amines. Structures of compounds were confirmed by IR, ${ }^{1} \mathrm{H}$ NMR, mass spectrometry and elemental analysis. ${ }^{13} \mathrm{C}$ NMR spectra of a few selected compounds were recorded. Spectral data are in agreement with the proposed structures. ${ }^{1} \mathrm{H}$ NMR spectra of compounds showed signals corresponding to aromatic, aliphatic, acetamide and $\mathrm{NH}$ protons. The singlet around $\delta 3.30\left(\mathrm{COCH}_{2}\right)$ and the broad singlet around $\delta 10.00 \mathrm{ppm}\left(\mathrm{NH}, \mathrm{D}_{2} \mathrm{O}\right.$ exchangeable) indicate the presence of $\mathrm{NHCOCH}_{2} \mathrm{~N}$ linkage in all compounds. Distortionless enhancement by polarization transfer (DEPT) experiments were employed to differentiate between primary and tertiary carbons from secondary and quaternary carbons. The ${ }^{13} \mathrm{C}$ NMR spectra of the compounds agree with the suggested structures. Moreover, the infrared spectra of the synthesized compounds show characteristic absorption bands of $\mathrm{NH}$ (amide group, $\left.\sim 3400 \mathrm{~cm}^{-1}\right)$, conjugated $\mathrm{C}=\mathrm{O}\left(\sim 1700 \mathrm{~cm}^{-1}\right), \mathrm{CONH}\left(\sim 1665 \mathrm{~cm}^{-1}\right)$ in addition to
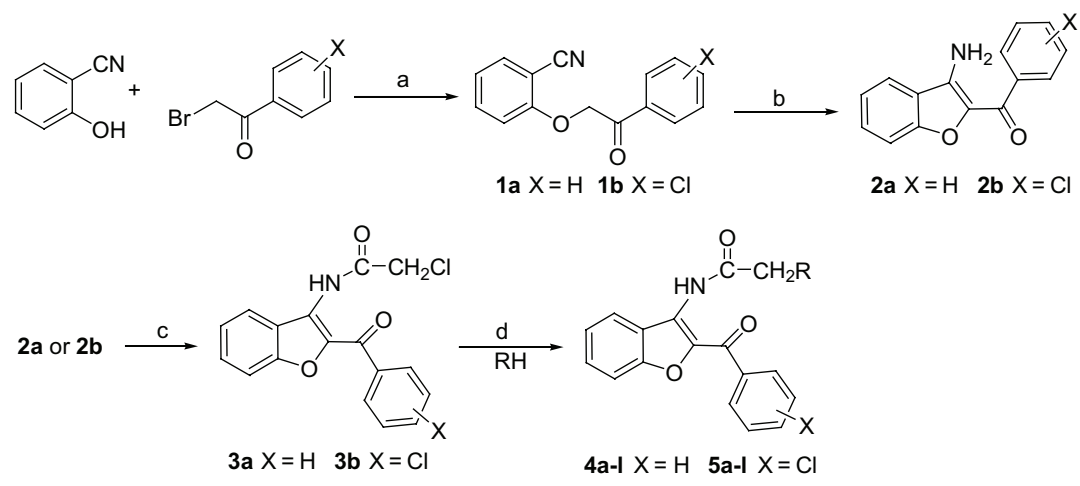

Scheme 1

Reagents and conditions: a) DMF, $\mathrm{K}_{2} \mathrm{CO}_{3}$, stir, $2 \mathrm{~h}$; b) $\mathrm{MeOH}, \mathrm{MeONa}$, stir, 1 h; c) dioxane, DIMAP, $\mathrm{ClCH}_{2} \mathrm{COCl}, 60^{\circ} \mathrm{C}, 5 \mathrm{~h}$; d) dioxane, sec. amine (RH), reflux, $4 \mathrm{~h}$, $\mathrm{RH}$ : piperidine $4 \mathrm{a}$, 5a; 2-methyl piperidine $4 \mathrm{~b}, 5 \mathrm{~b}$; 4-methyl piperidine $4 \mathrm{c}, 5 \mathrm{c}$; 2,6-dimethyl piperidine $4 \mathrm{~d}, 5 \mathrm{~d}$; 4-ethylpiperazine $4 \mathrm{e}$, 5e; 4-(2-furanoyl)piperazine 4f, 5f; 4-(2-flurophenyl)piperazine $4 \mathrm{~g}$, 5g, 4-(2-pyridyl)piperazine $4 \mathrm{~h}$, $5 \mathrm{~h}$; cyclohexyl(methyl)amine $4 \mathbf{i}$, 5i; morpholine $4 \mathbf{j}$, $5 \mathbf{j}$; dicyclohexylamine $4 \mathbf{k}, 5 \mathbf{k}$; dipropylamine $4 \mathbf{l}$ and 4-methyl piperazine 51 . 
Table II. Effects of tested compounds $4 \boldsymbol{a}-\boldsymbol{l}, \mathbf{5 a}-\mathbf{l}$ and phenytoin on MES induced convulsions in mice $(\mathrm{n}=6)$

\begin{tabular}{|c|c|c|c|c|c|c|c|}
\hline \multirow{2}{*}{ Compd. } & \multirow{2}{*}{$\begin{array}{c}L D_{50} \\
{\left[\mathrm{mg} \mathrm{kg}^{-1}\right.} \\
\left.\left(\mathrm{mmol} \mathrm{kg}^{-1}\right)\right]\end{array}$} & \multirow{2}{*}{$\log P^{a}$} & \multirow{2}{*}{$\begin{array}{c}E D_{50} \\
\left(\mathrm{mg} \mathrm{kg}^{-1}\right)\end{array}$} & \multirow{2}{*}{$\begin{array}{c}E D_{50} \\
\left(\mathrm{mmol} \mathrm{kg}^{-1}\right)\end{array}$} & \multirow{2}{*}{$\begin{array}{c}\text { Activity } \\
\text { compared to } \\
\text { phenytoin }\end{array}$} & \multicolumn{2}{|c|}{$\begin{array}{l}\text { Neurotoxicity dose } \\
\mathrm{mg} \mathrm{kg}^{-1}\left(\mathrm{mmol} \mathrm{kg}^{-1}\right)\end{array}$} \\
\hline & & & & & & $0.5 \mathrm{~h}$ & $4 \mathrm{~h}$ \\
\hline $4 a$ & - & 2.37 & 36.5 & 0.101 & 0.41 & $100(0.276)$ & - \\
\hline $4 b$ & - & 2.69 & 31.6 & 0.084 & 0.49 & $100(0.266)$ & - \\
\hline $4 c$ & - & 2.70 & 31.6 & 0.084 & 0.49 & $100(0.266)$ & $100(0.266)$ \\
\hline $4 d$ & - & 3.01 & 31.6 & 0.081 & 0.51 & $100(0.256)$ & - \\
\hline $4 e$ & - & 1.73 & 51.3 & 0.131 & 0.31 & $30(0.077)$ & $100(0.255)$ \\
\hline $4 \mathrm{f}$ & - & 1.18 & 97.0 & 0.212 & 0.19 & $30(0.066)$ & $100(0.219)$ \\
\hline $4 \mathrm{~g}$ & - & 3.63 & 31.6 & 0.069 & 0.59 & $100(0.219)$ & - \\
\hline $4 \mathrm{~h}$ & - & 2.85 & 31.6 & 0.072 & 0.57 & $100(0.227)$ & - \\
\hline $4 i$ & - & 3.18 & 31.6 & 0.081 & 0.51 & $100(0.256)$ & $300(0.769)$ \\
\hline $4 j$ & - & 1.24 & 73.1 & 0.201 & 0.21 & $100(0.275)$ & - \\
\hline $4 k$ & - & 4.73 & 36.5 & 0.079 & 0.52 & $100(0.218)$ & - \\
\hline 41 & - & 3.29 & 31.6 & 0.083 & 0.49 & $100(0.264)$ & $100(0.264)$ \\
\hline $5 a$ & - & 2.93 & 31.6 & 0.079 & 0.52 & $100(0.252)$ & $300(0.756)$ \\
\hline $5 b$ & - & 3.25 & 31.6 & 0.077 & 0.53 & $100(0.243)$ & $300(0.730)$ \\
\hline $5 c$ & 681 (1.657) & 3.26 & 23.4 & 0.057 & 0.72 & $100(0.243)$ & - \\
\hline $5 d$ & - & 3.56 & 31.6 & 0.074 & 0.55 & $100(0.235)$ & $300(0.706)$ \\
\hline $5 e$ & - & 2.29 & 36.5 & 0.085 & 0.48 & $30(0.070)$ & $100(0.235)$ \\
\hline $5 f$ & - & 1.73 & 127.6 & 0.259 & 0.16 & $30(0.061)$ & $100(0.203)$ \\
\hline $5 \mathrm{~g}$ & - & 4.18 & 31.6 & 0.064 & 0.64 & $100(0.203)$ & - \\
\hline $5 \mathrm{~h}$ & - & 3.40 & 36.5 & 0.077 & 0.53 & $100(0.211)$ & $300(0.632)$ \\
\hline $5 i$ & 681 (1.604) & 3.74 & 23.4 & 0.055 & 0.74 & $100(0.236)$ & - \\
\hline $5 \mathbf{j}$ & - & 1.80 & 73.1 & 0.183 & 0.22 & $100(0.251)$ & $300(0.753)$ \\
\hline $5 k$ & - & 5.29 & 36.5 & 0.074 & 0.55 & $30(0.061)$ & $100(0.203)$ \\
\hline 51 & - & 1.95 & 56.7 & 0.137 & 0.30 & $30(0.073)$ & $100(0.243)$ \\
\hline Phenytoin & $150(0.595)$ & 2.47 & $10.3(6.5)^{b}$ & 0.041 & 1.00 & $100(0.396)$ & $100(0.396)$ \\
\hline
\end{tabular}

$L D_{50}$ - median lethal dose; the amount of substance required to kill $50 \%$ of the test population.

$E D_{50}$ - median effective dose; the dose that produces a quantal effect (all or nothing) in $50 \%$ of the population.

${ }^{a} \log P$ value was calculated using ChemDraw Ultra V.11.

${ }^{\mathrm{b}}$ Experimental $E D_{50}$ value of phenytoin (9).

other absorption bands correlated to the assigned structures. Mass spectral data of the synthesized compounds are in agreement with the assigned structures and show the expected molecular ions $[\mathrm{M}+\mathrm{H}]^{+}$suggested by their molecular formulae. 


\section{Pharmacology}

All synthesized compounds were evaluated for anticonvulsant activity along with the neurotoxicity effect on mice. The $A L D_{50}$ (i.p.) of compounds $\mathbf{5} \mathbf{c}$ and $\mathbf{5 i}$ were 1.604 and 1.675 $\mathrm{mmol} \mathrm{kg}{ }^{-1}\left(681 \mathrm{mg} \mathrm{kg}^{-1}\right)$ body mass, respectively.

Anticonvulsant activity. - Table II indicates that the anticonvulsant activity of the examined compounds was lower than that of phenytoin. $E D_{50}$ values of tested compounds ranged from 0.055 to $0.259 \mathrm{mmol} \mathrm{kg}^{-1}$, while the $E D_{50}$ of phenytoin was $0.041 \mathrm{mmol} \mathrm{kg}^{-1}$ in mice. The relative potencies of tested compounds with respect to phenytoin were calculated by taking the ratio of the $E D_{50}$ of compounds over phenytoin. Among all the compounds examined, [N-(2-(4-chlorobenzoyl)benzofuran-3-yl)-2-(cyclohexyl(methyl)amino)-acetamide] (5i) and [N-(2-(4-chlorobenzoyl)benzofuran-3-yl)-2-(4-methylpiperidin-1-yl)-acetamide] (5c) demonstrated the highest anticonvulsant activity with anticonvulsant potency relative to phenytoin of 0.74 and 0.72 , respectively, whereas [( $N$-(2-(4-chlorobenzoyl)-benzofuran-3-yl)-2(4-(furan-2-carbonyl)-piperazin-1-yl)-acetamide] (5f) exhibited the lowest relative potency of 0.16 . Relative potencies of other compounds compared to phenytoin ranged from 0.21 to 0.64 .

The results showed that all the synthesized compounds (4a-1 and $5 \mathbf{a}-\mathbf{1})$ were found to be highly active against the MES test at a dose level of $30 \mathrm{mg} \mathrm{kg}^{-1}$, at a $0.5 \mathrm{~h}$ time interval, indicating their ability to prevent seizure spread at a relatively low dose. The results indicate that $p$-chlorobenzoyl derivatives $\mathbf{5 a - 1}$ were more active than the corresponding benzoyl derivatives $4 a-1$, probably due to higher partition coefficient and lipid solubility (log P). Apart from compounds $5 \mathrm{c}$ and $5 \mathrm{i}$, compounds $4 \mathrm{~b}, 4 \mathrm{c}, 4 \mathrm{~d}, 4 \mathrm{~g}, 4 \mathrm{~h}, 4 \mathrm{i}, 4 \mathrm{k}, 4 \mathrm{l}, 5 \mathrm{a}, 5 \mathrm{~b}, 5 \mathrm{~d}, 5 \mathrm{~g}$, 5h, and 5k showed promising activity, with $E D_{50}$ values ranging from 0.064 to $0.084 \mathrm{mmol}$ $\mathrm{kg}^{-1}$. Interestingly, it was observed that the substituted piperazine and piperidine [viz., 4-(2-flurophenyl)piperazinyl-(4g, 5g), 4-(pyridin-2-yl-)-piperazinyl-(4h, 5h), 4-methylpiperidinyl-(4c, 5c), 2,6-dimethylpiperidinyl-(4d, 5d), 2-methylpiperidinyl $(4 \mathbf{b}, 5 \mathbf{b})$ and piperidinyl 5a] derivatives were more active than other derivatives.

Neurotoxicity. - It is noteworthy that compound $5 \mathbf{k}$ was more neurotoxic than the corresponding benzoyl derivative [ $N$-(2-benzoylbenzofuran-3-yl)-2-(dicyclohexylamino)-acetamide] (4k) in spite of retaining the same effective doses. On the other hand, $\log P$ value

Table III. GABA assay for active compounds $5 i$ and $5 c$

\begin{tabular}{lccc}
\hline \multirow{2}{*}{ Compound (dose) } & \multicolumn{2}{c}{ GABA concentration $(\mu \mathrm{g} \text { per } 100 \mathrm{mg})^{\mathrm{a}}$} \\
\cline { 2 - 4 } & Midbrain & Medulla oblongata & Cerebellum \\
\hline Control & $32.12 \pm 3.85$ & $28.24 \pm 3.84$ & $21.45 \pm 2.18$ \\
$\mathbf{5 i}\left(100 \mathrm{mg} \mathrm{kg}^{-1}, 0.236 \mathrm{mmol} \mathrm{kg}^{-1}\right)^{\mathrm{b}}$ & $56.45 \pm 3.14$ & $40.21 \pm 3.82$ & $31.25 \pm 2.25$ \\
$\mathbf{5 c}\left(100 \mathrm{mg} \mathrm{kg}^{-1}, 0.243 \mathrm{mmol} \mathrm{kg}\right)^{\mathrm{b}}$ & $44.37 \pm 2.45$ & $36.07 \pm 2.91$ & $29.54 \pm 2.50$ \\
${\text { Clobazam }\left(30 \mathrm{mg} \mathrm{kg}^{-1}, 0.100 \mathrm{mmol} \mathrm{kg}^{-1}\right)^{\mathrm{b}}}^{6}$ & $64.14 \pm 3.08$ & $49.45 \pm 2.12$ & $38.45 \pm 2.18$ \\
\hline
\end{tabular}

${ }^{\mathrm{a}}$ Mean \pm SEM, $n=3$.

${ }^{\mathrm{b}}$ Significant increase $v$ s. control $(p<0.05)$. 
appears to significantly reduce potency and increase neurotoxicity of the compounds. Among all compounds, $\mathbf{4 e ,} \mathbf{4 f}, \mathbf{5 e}, \mathbf{5 f}, \mathbf{5 k}$ and $\mathbf{5 l}$ showed neurotoxicity even at the lowest dose of $30 \mathrm{mg} \mathrm{kg}^{-1}$ (after $0.5 \mathrm{~h}$ ) (Table II). It was observed that all the synthesized compounds exerted anticonvulsant activity, which may be due to their interaction with the receptor site and essential pharmacophoric features present in these compounds.

GABA level in brain. - Compounds $5 \mathbf{c}, 5 \mathbf{i}$ and clobazam significantly increased $(p<0.05)$ the GABA level in brain compared to the control (Table III), suggesting that the observed anticonvulsant effect may be mediated through GABA-neurotransmission.

\section{Pharmacophore modeling}

$3 D$ pharmacophore generation. - In the pharmacophore model generation, the already reported protocol was used in which the highest weight was assigned to the most active compound $5 \mathbf{i}$. The highest weight assignment was carried out by assigning the highest values 2 and 0 in the principal and maximum omitting features column which ensured mapping of all the features of this compound considering it the most active ones. All the remaining compounds were respectively assigned a value of 1 and 1 which ensured that there should be at least one mapping for each of the remaining compounds so as to develop a meaningful hypothesis or pharmacophore model. All other parameters were kept at default. The ten hypotheses generated had the scores ranging from 138.32 to 131.10 (Table III). The entire ten hypotheses contain six features, two hydrogen bond acceptor (HBA) common to all hypotheses, one hydrogen bond donor (HBD), one positively ionisable (PI), one aromatic ring (AR) and one hydrophobic (Z). Hypo-1 was selected as it significantly maps all the features of most active compounds and also has maximum features. Out of the ten hypotheses, Hypo-1 was selected as it maps all the features of the most active compounds from the training set molecule. The two HBA functions map on the oxygen atom of the benzofuran ring and the carbonyl functionality of the methanone part of benzofuran-2-yl(4-chlorophenyl)-methanone of the most active compound from the training set $5 \mathbf{i}$. The
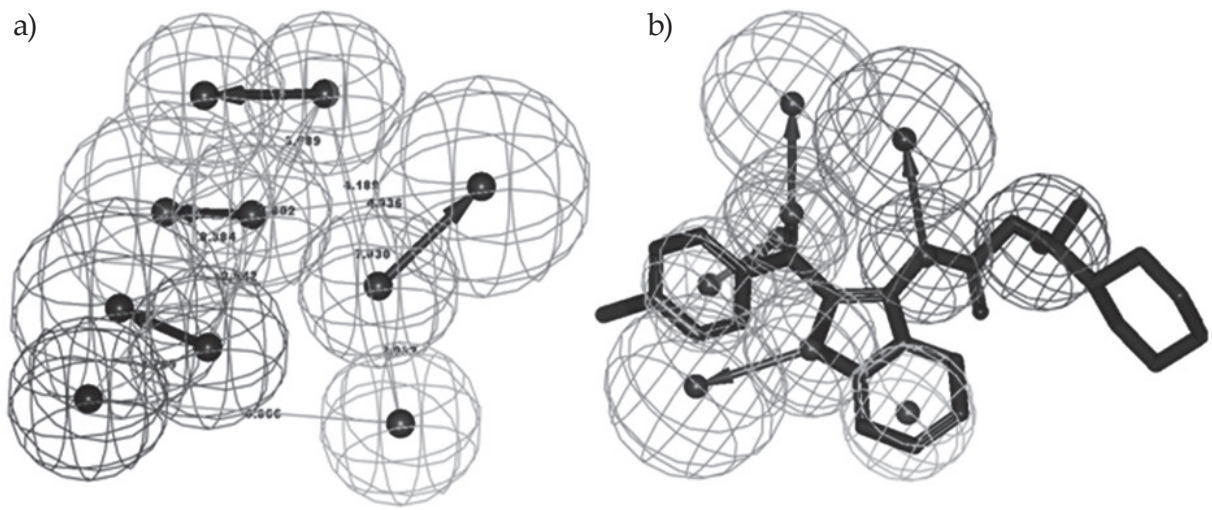

Fig. 1. Generated pharmacophore models and overlays: a) pharmacophore model for synthesized anticonvulsant compounds along with its inter-feature distance constraints, b) overlay of the most active compound $5 \mathbf{i}$ in the training set. 
A.-K. Shakya et al:: Design, synthesis and evaluation of benzofuran-acetamide scaffold as potential anticonvulsant agent, Acta Pharm. 66 (2016) 353-372.

Table IV. Summary of the pharmacophore models generated for the training set of compounds

\begin{tabular}{cccccc}
\hline Hypothesis & Features $^{\mathrm{a}}$ & Rank & Direct hit $^{\mathrm{b}}$ & Partial hit $^{\mathrm{c}}$ & Maximal fit $^{\text {B }}$ \\
\hline 1 & RPHDAA & 138.973 & 1111111110 & 0000000001 & 6 \\
2 & RPHDA & 134.672 & 1111111111 & 0000000000 & 5 \\
3 & RPHAA & 133.891 & 1111111111 & 0000000000 & 5 \\
4 & RPHAA & 133.891 & 1111111111 & 0000000000 & 5 \\
5 & RRPAA & 133.89 & 1111111111 & 0000000000 & 5 \\
6 & RRPAA & 133.89 & 1111111111 & 0000000000 & 5 \\
7 & RPHAA & 133.887 & 1111111111 & 0000000000 & 5 \\
8 & RRPAA & 133.702 & 1111111111 & 00000000000 & 5 \\
9 & PHHDAA & 133.136 & 1111111110 & 0000000001 & 6 \\
10 & RPHAA & 132.885 & 1111111111 & 0000000000 & 5 \\
\hline
\end{tabular}

${ }^{a} \mathrm{R}$ - aromatic ring; D - hydrogen bond donor; $\mathrm{A}$ - hydrogen bond acceptor; $\mathrm{H}$ - hydrophobic group, $\mathrm{P}$ - positive ionisable group.

b Direct hit; all features of the hypothesis are mapped. Direct hit = 1 means ,yes" and direct hit = 0 means ",no".

c Partial hit; partial mapping of the hypothesis. Partial hit = 1 means „yes" and partial hit = 0 means "no".

hydrophobic feature maps well on the benzene ring of the benzofuran nucleus. The $\mathrm{NH}$ function of the acetamide linkage of the cyclohexyl-(methyl)-amino-acetamide part of $5 \mathbf{i}$ is mapped for the HBD function of the pharmacophore while the nitrogen atom indicates the PI feature of pharmacophore. Finally, the RA function of the pharmacophore is supported by the 4-chlorobenzoyl substitution on the benzofuran nucleus. Mapping of the most active compound $5 \mathbf{i}$ from the series $5 \mathbf{a}-\mathbf{1}$ (fit value 6) on the developed pharmacophore, along with the pharmacophore model with inter-feature distance, is represented in Figs. 1a,b.

Ligand pharmacophore mapping. - Hypo-1 was used as a query for mapping the external or standard compounds used as drugs (Table IV). The drugs, viz., phenytoin, carbamazepine, phenobarbital and ralitolin, were used for validation of the pharmacophore model. The ligand pharmacophore mapping protocol was used, allowing for the best conformation search method from the Discovery Studio 2.0 (Telesis Court, San Diego, CA, USA). The ligand pharmacophore mapping reveals that compounds synthesized and tested for anticonvulsant activity have the common pharmacophore features required for the targeted activity. Figs. 2a-d indicate the mapping of these compounds on the developed pharmacophore. The pharmacophore mapping of these compounds on standard drugs preliminarily suggests that these compounds may act with the same mechanism of action as that of the known drugs.

Molecular modeling and docking studies. - In order to evaluate the docking results, different scoring functions were analyzed for the two most active compounds and the reference standard compounds. The results of the docking runs are represented in Table V. The most active compounds from the series were analyzed for their binding properties at the GABA-AT enzyme binding site at the Lys-329 residue of GABA-AT, as described $(25,26)$. 


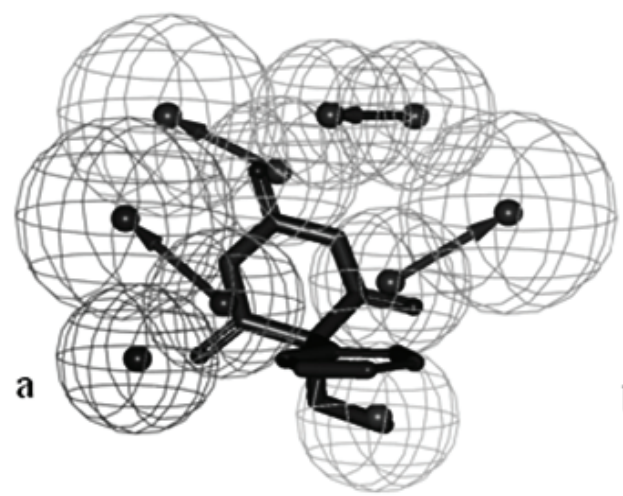

b
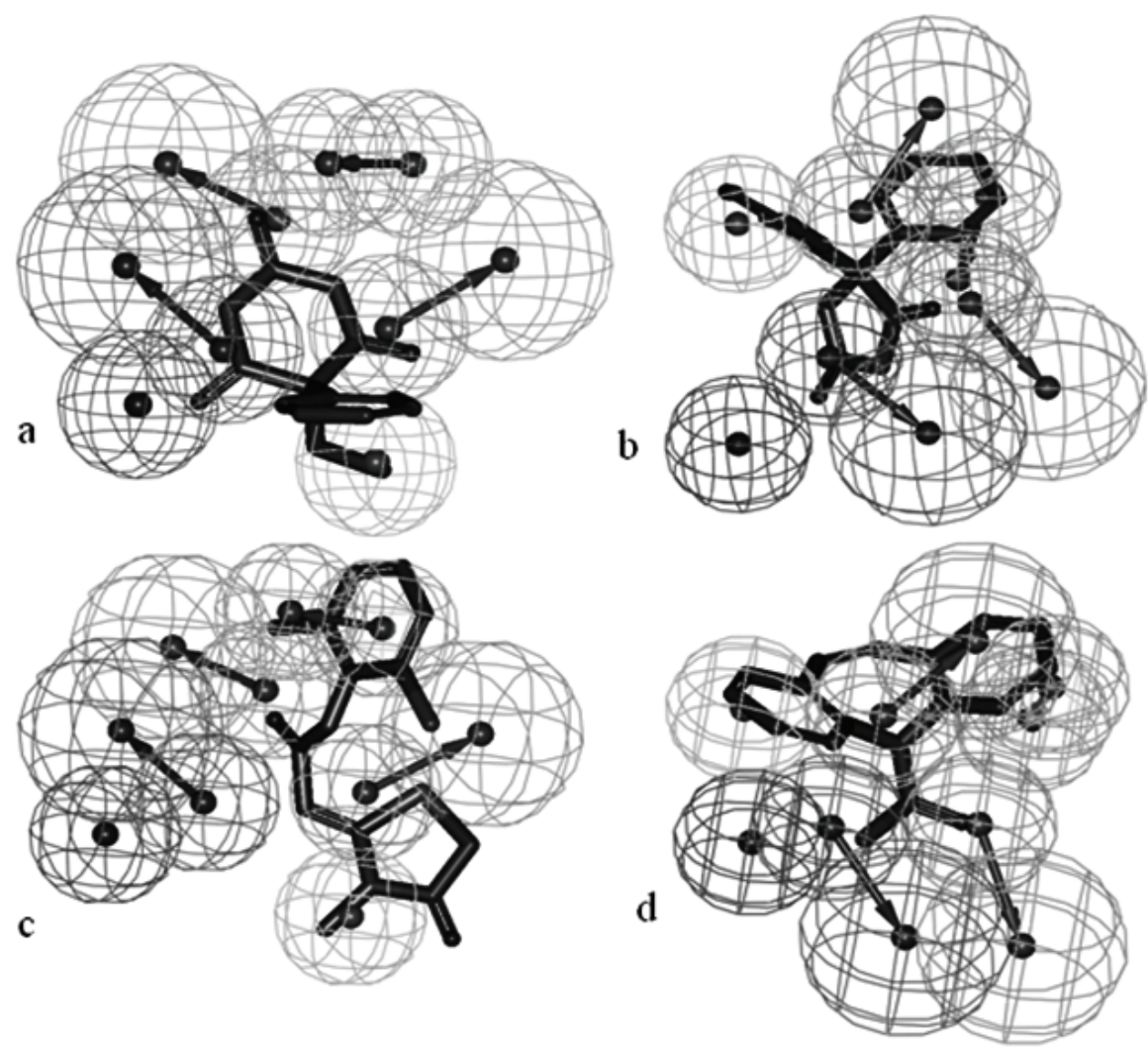

Fig. 2. Overlay of the standard compounds, viz., a) phenobarbital, b) phenytoin, c) ralitolin and d) carbamazepine used in this study.

As shown in Table IV, compounds show high selectivity at GABA-AT with interactions of the important amino acids Arg-192, Ser-137, Thr-353 and Lys-329. Compounds 5c (Moldock score -334.844 and re-rank score -188.461) and compound 5i (Moldock score -314.576 and re-rank score -163.085) showed excellent binding interactions compared to the internal standard/ reference compound phenytoin (Moldock score -291.531and re-rank score -244.326). Molecular interactions of these compounds in close proximity of Lys-329 explain the high GABA-AT selectivity. The docking poses of compounds $\mathbf{5 c}, \mathbf{5 i}$ and phenytoin are shown in Fig. 4. The internal aldimine linkage between Lys-329 and pyridoxal 5'-phosphate cofactor of the enzyme was broken. Instead, a covalent ternary adduct was formed between the inhibitor and the lysine residue. The affinity of these compounds with respect to the known standard drugs from this category was carried out in a Molegro virtual docker. It shows that these compounds have comparatively good binding affinities in the GABA-AT active site. The results of the docking studies are represented in Fig. 3 and Tables IV and V. 
A.-K. Shakya et al.: Design, synthesis and evaluation of benzofuran-acetamide scaffold as potential anticonvulsant agent, Acta Pharm 66 (2016) 353-372.

Table V. Docking based predicted potencies in terms of the Moldock score, re-rank score and binding affinities of the synthesized compounds and of standard reference compounds

\begin{tabular}{lccc}
\hline Compd. & Moldock score & Re-rank score & Binding affinity predicted \\
\hline $\mathbf{5 c}$ & -334.844 & -188.461 & -26.8359 \\
$5 \mathbf{i}$ & -314.576 & -163.085 & -35.4334 \\
Phenytoin & -291.531 & -244.326 & -34.7004 \\
Carbamazepine & -201.409 & -129.489 & -31.6291 \\
Phenobarbital & -202.81 & -169.056 & -21.9851 \\
Ralitolin & -249.683 & -188.369 & -30.9745 \\
\hline
\end{tabular}

a)

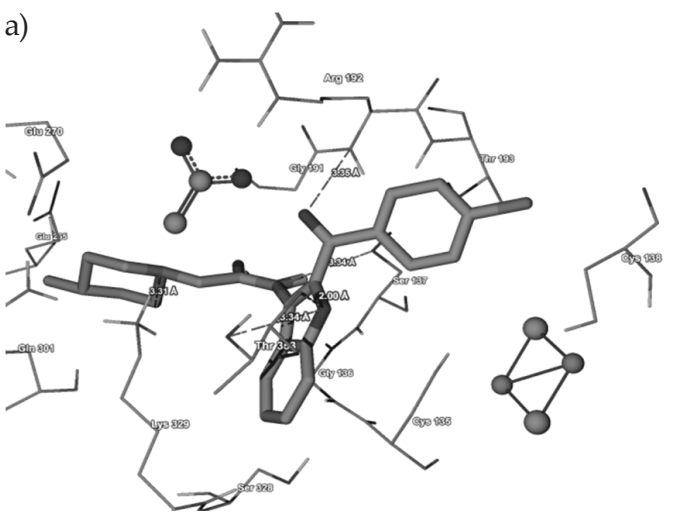

c)

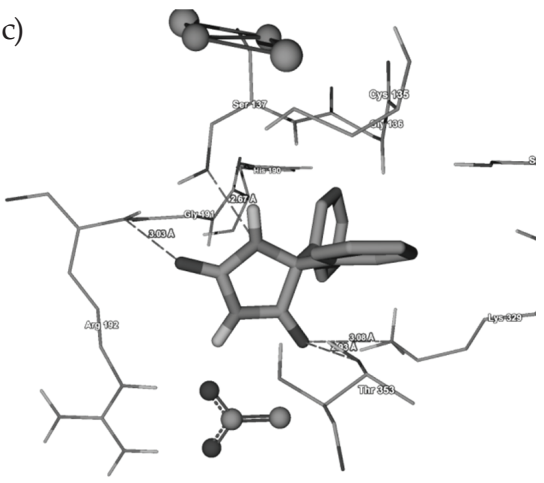

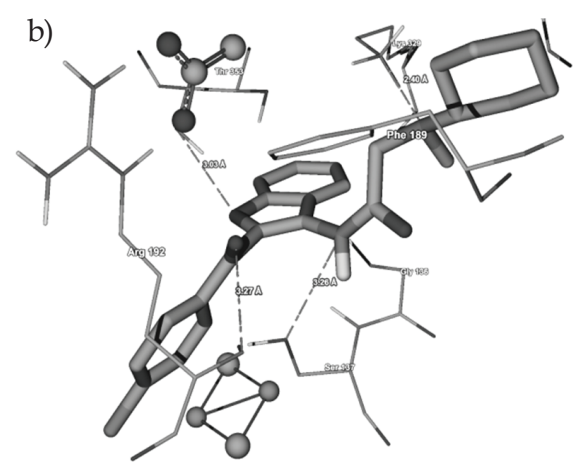

Fig. 3. Docking predicted poses and interactions between: a) compound $5 \mathrm{c}$, b) compound $5 \mathbf{i}$ and c) phenytoin, and amino acids in the active site of 4-aminobutyrate-aminotransferase (GABA-AT) (PDB code 1OHV).

\section{CONCLUSIONS}

In the present study, a series of benzofuran derivatives were synthesized, characterized and evaluated for their anticonvulsant activity. The title compounds (4a-1, 5a-1) fulfill all the pharmacophoric structural requirements, i.e., the presence of benzofuran as the 
hydrophobic portion, $\mathrm{C}=\mathrm{O}$ as the hydrogen bond acceptor, $\mathrm{NHCO}$ or the terminal nitrogen as the hydrogen bond donor and the hydrophobic aryl ring responsible for metabolism, which were well corroborated by the known standard drugs. The majority of the compounds demonstrated significant anticonvulsant activity, although lower than that of the reference compound phenytoin. Strategic manipulation is required to synthesize compounds with enhanced activity and lower neurotoxicity. Based on our docking results, the binding interactions and the occupation of these compounds in the active site by residues and the binding affinities with respect to standard compounds will provide a new direction for further standardization of these molecules.

Acknowledgments. - The authors are greatful to the Dean, Faculty of Pharmacy, Integral University, Lucknow 226026 (U.P.), India, Faculty of Pharmacy and Medical Sciences, and Higher Education \& Research, Al-Ahliyya Amman University, Amman, Jordan, for providing necessary facilities. The authors are also greatful to SAIF, CDRI, Lucknow, India, and The University of Jordan, Amman, Jordan, for elemental and spectral analyses.

\section{REFERENCES}

1. World Health Organization Information Kit on Epilepsy - What you can do, WHO, Geneva 2015, pp.1-42; http://www.who.int/mental_health/neurology/epilepsy/epilepsy_global_toolkit.pdf, last access date December 19, 2015.

2. D. Schmidt and W. Loscher, Drug resistance in epilepsy, Putative neurobiologic and clinical mechanisms, Epilepsia 46 (2005) 858-877; DOI: 10.1111/j.1528-1167.2005.54904.x.

3. D. Battino, G. Dukes and E. Perucca, Anticonvulsant, in Meyler's Side Effects of Drugs - An Encylcopedia of Adverse Reactions and Interactions (Eds. M. N. G. Dukes and J. K. Aronson), $14^{\text {th }}$ ed., Elsevier Science Publishers, New York 2000, pp. 164-197.

4. J. M. L. Lima, The new drugs and the strategies to manage epilepsy, Curr. Pharm. Des. 6 (2008) 873-878; DOI: 10.2174/1381612003400308.

5. A. Thiry, J. M. Dogne, C. T. Supuran and B. Masereel, Carbonic anhydrase inhibitors as anticonvulsant agents, Curr. Top. Med. Chem. 7 (2007) 855-864; DOI: 10.2174/156802607780636726.

6. M. J. Brodie, Do we need any more new antiepileptic drugs? Epilepsy Res. 45 (2001) 3-6; DOI: 10.1016/S0920-1211(01)00203-0.

7. C. L. P. Deckers, P. Genton, G. J. Sills and D. Schmidt, Current limitations of antiepileptic drug therapy, a conference review, Epilepsy Res. 53 (2003) 1-17; DOI: 10.1016/S0920-1211(02)00257-7.

8. B. Malawska, New anticonvulsant agents, Curr. Top. Med. Chem. 5 (2005) 69-85; DOI: $10.2174 / 1568026053386944$.

9. D. Choi, J. P. Stables and H. Kohn, Synthesis and anticonvulsant activities of N-benzyl-2-acetamido-propionamide derivatives, J. Med. Chem. 39 (1996) 1907-1916; DOI: 10.1021/jm9508705.

10. A. H. Tarikogullari, F. S. Kilic, K. Erol and V. Pabuccuoglu, Synthesis and anticonvulsant activity of some alkanamide derivatives, Arzneimittelforsch 60 (2010) 593-598; DOI: 10.1055/s-0031-1296331.

11. S. N. Pandeya, P. Yogeeswari and J. P. Stables, Synthesis and anticonvulsant activity of 4-bromophenyl substituted aryl semicarbazones, Eur. J. Med. Chem. 35 (2000) 879-886; DOI: 10.1016/S02235234(00)01169-7.

12. K. M. Basavaraja, V. P. Vaidya and C. Chandrashekhar, Synthesis of benzofuro[3,2-e]-1,4-diazepines of pharmacological interest, Eur. J. Chem. 5 (2008) 567-571; DOI: 10.1155/2008/920926.

13. K. M. Dawood, H. Abdel-Gawad, E. A. Rageb, M. Ellithey and H. A. Mohamed, Synthesis, anticonvulsant, and anti-inflammatory evaluation of some new benzotriazole and benzofuran-based heterocycles, Bioorg. Med. Chem. 14 (2006) 3672-3680; DOI: 10.1016/j.bmc.2006.01.033. 
14. H. Rajak, C. K. Behera, R. S. Pawar, P. K. Singour and M. D. Kharya, A novel series of 2,5-disubstituted 1,3,4-thiadiazoles as potential anticonvulsant agent, Chin. Chem. Lett. 21 (2010) 1149-1152; DOI: 10.1016/j.cclet.2010.04.012.

15. I. R. Sadarangani, S. Bhatia, D. Amarante, I. Lengyel and R. A. Stephani, Synthesis, resolution and anticonvulsant activity of chiral $N$-1'-ethyl, $N$-3'-(1-phenylethyl)-( $R, S)-2^{\prime} H, 3 H, 5^{\prime} H$-spiro-(2benzofuran-1,4'-imidazolidine)-2',3,5'-trione diastereomers, Bioorg. Med. Chem. Lett. 22 (2012) 2507-2509; DOI: 10.1016/j.bmcl.2012.02.005.

16. S. Rádl, P. Hezký, J. Urbánková, P. Váchal and I. Krejči, Synthesis and analgesic activity of some 1-benzofurans, 1-benzothiophenes and indoles, Collect. Czech. Chem. Commun. 65 (2000) 280-296.

17. C. Aswathanarayanappa, E. Bheemappa, Y. D. Bodke, V. K. Bhovi, R. Ningedowda, M. C. Shivakumar, S. K. Peethambar and S. Telkar, 5-Phenyl-1-benzofuran-2-yl derivatives, synthesis, antimicrobial, and antioxidant activity, Med. Chem. Res. 22 (2013) 78-87; DOI: 10.1007/s00044-12-0017-y.

18. T. Kosmalski, J. Kutkowska, A. K. Gzella and A. Nowakiewicz, New heterocyclic oxime ethers of 1-(benzofuran-2-yl)ethan-1-one and their antimicrobial activity, Acta Pol. Pharm. 72 (2015) 289-295.

19. J. Cho, C. Park, Y. Lee, S. Kim, S. Bose, M. Choi, A. S. Kumar, J. K. Jung and H. Lee, Neuroprotective and antioxidant effects of novel benzofuran-2-carboxamide derivatives, Biomol. Ther. (Seoul). 23 (2015) 275-282; DOI: 10.4062/biomolther.2015.030.

20. X. D. Yang, W. C. Wan, X. Y. Deng, Y. Li, L. J. Yang, L. Li and H. B. Zhang, Design, synthesis and cytotoxic activities of novel hybrid compounds between 2-phenylbenzofuran and imidazole, Bioorg. Med. Chem. Lett. 22 (2012) 2726-2729; DOI: 10.1016/j.bmcl.2012.02.094

21. M. Choi, H. Jo, H. J. Park, A. S. Kumar, J. Lee, J. Yun, Y. Kim, S. B. Han, J. K. Jung, J. Cho, K. Lee, J. H. Kwak and H. Lee, Design, synthesis, and biological evaluation of benzofuran- and 2,3-dihydrobenzofuran-2-carboxylic acid N-(substituted)phenylamide derivatives as anticancer agents and inhibitors of NF-кB, Bioorg. Med. Chem. Lett. 25 (2015) 2545-2549; DOI: 10.1016/j.bmcl.2015.04.050.

22. H. Kwiecień, A. Goszczyńska and P. Rokosz, Benzofuran small molecules as potential inhibitors of human protein kinases, A Review, Curr. Pharm. Des. 22 (2015); DOI: 10.2174/1381612822666151209152457.

23. B. Waltenberger, K. Wiechmann, J. Bauer, P. Markt, S. M. Noha, G. Wolber, J. M. Rollinger, O. Werz, D. Schuster and H. Stuppner, Pharmacophore modeling and virtual screening for novel acidic inhibitors of microsomal prostaglandin E2 synthase-1 (mPGES-1), J. Med. Chem. 54 (2011) 31633174; DOI: 10.1021/jm101309g.

24. Z. Wang, S. Zhang, H. Jin, W. Wang, J. Huo, L. Zhou, Y. Wang, F. Feng and L. Zhang, AngiotensinI-converting enzyme inhibitory peptides, Chemical feature based pharmacophore generation, Eur. J. Med. Chem. 46 (2011) 3428-3433; DOI: 10.1016/j.ejmech.2011.05.007.

25. S. K. Bansal, B. N. Sinha and R. L. Khosa, Docking-based virtual screening of Schiff's bases of GABA: a prospective to novel GABA-AT inhibitors, Med. Chem. Res. 21 (2012) 3063-3072; DOI: 10.1007/s00044-011-9843-6.

26. R. Sinha, S. U. V. Singh, R. L. Khosa, J. P. Stables and J. Jain, Nicotinic acid hydrazones: a novel anticonvulsant pharmacophore, Med. Chem. Res. 20 (2011) 1499-1504; DOI: 10.1007/s00044-0109396-0.

27. W. Loscher, C. P. Fassbender and B. Nolting, The role of technical, biological and pharmacological factors in the laboratory evaluation of anticonvulsant drugs. II. Maximal electroshock seizure models, Epilepsy Res. 8 (1991) 79-94.

28. H. G. Vogel. Drug Discovery and Evaluation. Pharmacological Assays, 2nd ed., Springer, Berlin 2002. 398-399, 422-427.

29. P. Yogeeswari, D. Sriram, R. Thirumurugan, J. V. Raghavendran, K. Sudhan, R. K. Pavana and J. Stables, Discovery of N-(2,6-dimethylphenyl)-substituted semicarbazones as anticonvulsants: Hybrid pharmacophore-based design, J. Med. Chem. 48 (2005) 6202-6211; DOI: 10.1021/jm050283b. 
30. A. K. Shakya, G. K. Patnaik and P. Mishra, Synthesis and biological activity of 2-substituted ethanamido-5-alkyl-1,3,4-thiadiazoles: Part-III, Acta Pharm. Turc. 42 (2000) 56-63.

31. R. B. Brooks, R. E. Bruccoleri, B. D. Olafson, D. J. States, S. Swaminathan and M. Karplus, CHARMM-a program for macromolecular energy, minimization, and dynamics calculations, $J$. Comp. Chem. 4 (1983) 187-217; DOI: 10.1002/jcc.540040211.

32. R. D. K. Gehlhaar, D. Bouzida and P. A. Rejto, Fully Automated and Rapid Flexible Docking of Inhibitors Covalently Bound to Serine Proteases, in: Evolutionary Programming VII, Proceedings of the $7^{\text {th }}$ International Conference EP98, San Diego, March 25-27, 1998, Springer, London 1998, pp. 449-461; DOI: 10.1007/BFb0040797.

33. J. M. Yang and C. C. Chen, Gemdock, A generic evolutionary method for molecular docking, Proteins 55 (2004) 288-304; DOI: 10.1002/prot.20035.

34. V. M. Balaramnavar, R. Srivastava, N. Rahuja, S. Gupta, A. K. Rawat, S. Varshney, H. Chandasana, Y. S. Chhonker, P. K. Doharey, S. Kumar, S. Gautam, S. P. Srivastava, R. S. Bhatta, J. K. Saxena, A. N. Gaikwad, A. K. Srivastava and A. K. Saxena, Identification of novel PTP1B inhibitors by pharmacophore based virtual screening, scaffold hopping and docking, Eur. J. Med. Chem. 87 (2014) 578-594; DOI: 10.1016/j. ejmech.2014.09.097. 